\section{Carotenoids of Some Brazilian Freshwater Gastropods of the Genus Pomacea}

VERY few reports are available on the carotenoids of freshwater molluscs ${ }^{1-3}$. The early researches of Kruckenberg (1882) and of MacMunn (1883) on the pigments of Helix pomatia revealed the presence of a not well-characterized carotenoid and of some chlorophyll in the liver of this snail. Lönnberg studied extensively the pigments of marine molluscs, and Lederer described two new carotenoids in the marine species Pectunculus glycymeris and Pecten maximus ${ }^{4,5}$.

In a short communication on the lipochromes of Pila glauca, a South American freshwater species, Comfort reported that the eggs and the 'uterine gland' were bright red in colour and that the pigment could be easily extracted by crushing the material with water ${ }^{8}$. On partition between 90 per cent methanol and petrol ether most of the pigment appeared in the hypophasic fraction. The intact pigment in formol-fixed embryos showed a single spectral band at $550 \mathrm{~m} \mu$. However, the pigments were neither separated nor characterized.

More recently, Cheesman isolated the chromoprotein from the eggs of the water snail Pomacea canaliculata (Orb.) and was able to study some of its properties. From extensive chromatographic and spectrographic analysis he showed that the pigment resembles astacene from lobster hypodermis but its identity was not definitely established?.

Having at our disposal several batches of eggs and of living molluscs belonging to the genus Pomacea (Pomacea, Perry, is the actual name for the genus Ampullaria which is very close to $P i l a^{8}$. We must remark that Pila is not found in Brazil and Pila glauca belongs to the genus Pomacea ${ }^{9}$ ), it seemed of interest to investigate the distribution and separa. tion of their pigments. $P$. haustrum and $P$. dolioides lay bright red eggs, and the yolk gland shows the same deep colour, whereas in $P$. sordida the colour is orange-yellow and in $P$. decussata light green. These differences in colour seemed to be related to the diet of these snails, since $P$. haustrum and $P$. dolioides are carnivorous-omnivorous and $P$. sordida is mainly herbivorous. The analysis of these biochromes showed also that the carnivorous species presented almost exclusively xanthophyll esters and free xanthophylls and the herbivorous one predominantly carotene.

The separation of the carotenoids was made by the partition test with immiscible solvents. The distribution of the pigments in the epiphase and hypophase after saponification with 10 per cent alcoholic potassium hydroxide solution is given in Table 1.

As shown in Table 1, P. haustrum and P. dolioides contained free xanthophylls and xanthophyll esters and a little carotene. $P$. sordida and $P$. decussata were

Table 1. Distribution of Carotenoids of Some Spedes of Pomacea

\begin{tabular}{|c|c|c|c|}
\hline \multirow{2}{*}{ Species } & \multicolumn{3}{|c|}{$\begin{array}{l}\text { Distribution of pigments between } 90 \text { per cent } \\
\text { methanol and petroleum ether }\end{array}$} \\
\hline & $\begin{array}{c}\text { Before } \\
\text { saponiflcation }\end{array}$ & $\begin{array}{c}\text { After } \\
\text { saponification }\end{array}$ & $\begin{array}{l}\text { Carotenoids } \\
\text { characterized }\end{array}$ \\
\hline P. haustrum & Mos & Most & Xanthophyll \\
\hline P. dolioides & $\begin{array}{l}\text { epiphasic } \\
\text { Mostly }\end{array}$ & $\begin{array}{l}\text { hypop } \\
\text { Mostly }\end{array}$ & $\begin{array}{l}\text { esters } \\
\text { Xanthophyll }\end{array}$ \\
\hline & epiphasic & hypophasic & esters \\
\hline $\begin{array}{l}P . \text { sordida } \\
P . \text { decussata }\end{array}$ & $\begin{array}{l}\text { Epiphasic } \\
\text { Epiphasic }\end{array}$ & Epiphasic & $\begin{array}{l}\text { Carotene } \\
\text { Carotene }\end{array}$ \\
\hline
\end{tabular}

found to contain only carotene. The epiphasic carotenoids were chromatographed in a magnesium oxide-Celite' mixture $(3: 1)$ and the hypophasic in calcium carbonate. Besides $\beta$-carotene there has been detected a band corresponding to $\alpha$-carotene. The hypophasic pigments were shown to be a mixture of three xanthophylls.

Purified carotene extract exhibited an absorption maximum at $450 \mathrm{~m} \mu$ and the predominant hypophasic xanthophyll one at $480-490 \mathrm{~m} \mu$. A tentative attempt to modify the carotenoid distribution of the eggs by feeding the herbivorous species a strictly animal diet was unsuccessful. However, the constancy of the carotene in the eggs, liver and yolk gland of these species and the predominance of xanthophyll esters in the carnivores are in accordance with the general rule for other invertebrate animals, that is, that the herbivores store carotene and the carnivores tend to store xanthophylls ${ }^{3}$.

The carotenoids existing in the eggs are stored in the liver of the newly hatched young animals, which could be easily shown in the apex of the shell where the liver is located. In the adult female the pigments concentrated in the yolk gland originated probably from the liver. Therefore, the cycle of the carotenoids in these snails may be visualized tentatively as follows :

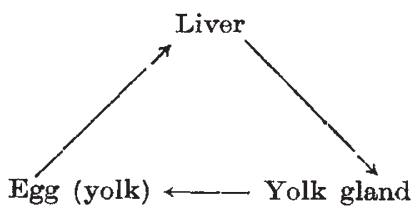

A study of the distribution and depletion of the liver and yolk gland carotenoids is in progress.

I wish to thank Prof. H. Souza Lopes, of the Department of Zoology, Instituto Oswaldo Cruz, Rio de Janeiro, for the snails used in this work and for help in the dissection and identification of these animals.

Biochemical Laboratory,

Gmberto G. Villela

Instituto Oswaldo Cruz, Rio de Janeiro. Feb. 10.

" Karrer, P., and Jucker, E., "Carotenoids" (English translation) (Elsevier Pub. Co., New York, Amsterdam, London, 1950).

"Goodwin, T. W., "The Comparative Blochemistry of Carotenoids" (Chapman and Hall, Ltd., London, 1952).

s Fox. D. L., "Animal Biochromes and Structural Colours" (Cambridge Univ. Press, 1953).

4 Lonnberg, E., Ark. Zool., 26A, 1 (1933).

"Lederer, E., Bull. Soc. Chim. Biol., 20, 554 (1938).

- Comfort, A., Nature, 160, 333 (1947).

"Cheesman, D. F., Biochem. J., 58, 38 (1954).

${ }^{3}$ Lopes, S. H., Rev. Brasil. Biol., 15, 203 (1955).

- Thiele, J., "Handbuch der Systematischen Weichtierkunde", 2 vol. (G. Fischer, Jena, 1929-34).

\section{Absence of Keratin in Teleost Epidermis}

IT has often been stated that the outermost layers of the teleost epidermis are keratinized ${ }^{1-4}$. Young ${ }^{5}$ says that, in the trout, ". . . the squamous epithe. lium of the epidermis provides the animal with a covering of keratin ...".

During a study of the epidermal structure of teleosts, the following species of fish were examined: Salmo salar, S. trutta, Esox lucius, Gadus callarias, G. virens, Molva molva, Onos mustelus, Tinca tinca, Phoxinus phoxinus, Anguilla anguilla, Conger conger, 